\title{
Conference Presentation
}

\section{The possibility of using Trichinella spiralis as an experimental model in the field of high dilutions}

\author{
Olga Borisovna Zhdanova ${ }^{1}$, Amina Aslanovna Haidarova ${ }^{2}$, ludmila Alexandrovna \\ Napisanova², Dimitri Rossohin1, Olga Lozhenicina1 \\ ${ }^{1}$ Department of Histology, Embryology and Cytology of Stomatologic (Dentistry) Faculty KSMA \\ ${ }^{2}$ Moscow Institute of Parasitology \\ Email: oliabio@yandex.ru
}

\section{Abstract \\ Background}

Trichinosis is a parasitic disease caused by ingestion larvae of Trichinella spiralis (TS). In Russia trichinosis of pigs is widely spreaded. Invasion occurs when human or animal eat contaminated meat. TS is adapted to many hosts, and due to its wide spread, there has always been a demand of safe alternatives for this infection. A lot of information has been gathered about sharp decreasing of quantity of trichinae in muscles at repeated invasion of predators. We took a chance of applying antigen to TS as a vaccine, however, rate of immunogenetic effect wasn't high. Therefore, in an experimental work, we decided to inject vaccine and immunomodulators together at the same time.

\section{Material and Methods}

We subjected rats infected with TS to conventional treatment (vaccine) along with Cina $6 \mathrm{cH}$. There were five groups as follows: The first group was injected antigen alone and no immunomodulators; the second group was injected antigen and Ronkoleikin; the third group was injected antigen and Sodium nucleinate, the fourth group was injected antigen and $\mathrm{Cina} \mathrm{C} 6 \mathrm{cH}$; and the fifth group was a control group, which was injected neither antigen nor immunomodulators. After 21 days of vaccination (or giving homeopathic medicine) rats were contaminated TS in a dose of 200germs/animal.

\section{Results}

The rats were euthanized after two months. They we then analysed for stomach contents and quantity of worms in muscles. The highest number of worms were found in fifth group (no antigen and no immunomodulators) (more than 2600 worms/animal. The quantity of worms in the second group (injection of antigen and Ronkoleikin) was in four times less than in the control group. The most efficient substance was Ronkoleikin (900+160 worms/animal); Sodium nucleinate $(1100 \pm 100$ worms/per animal); Cina C6cH (1400 \pm 50 worms/animal).

\section{OPEN ACCESS}

Cite as: Zhdanova OB, Haidarova AA, Napisanova JA, Rossohin D, Lozhenicina O. The possibility of using T.spiralis as an experimental model in the field of high dilutions. Proceedings of the XXIX GIRI Meeting; 2015 June 3 - 5; Verona (Italy). Int J High Dilution Res. 2015; 14(2): 60-61 


\section{Conclusion}

Cina $\mathrm{C} 6 \mathrm{cH}$ along with and others immunomodulators was able to exhibit protective effect against experimental trichinosis. Further research with rigorous designs is needed to explore the role of Cina in Trichinella spiralis.

Keywords: Trichinella spiralis; Cina; homeopathy

(C) International Journal of High Dilution Research.

Not for commercial purposes.

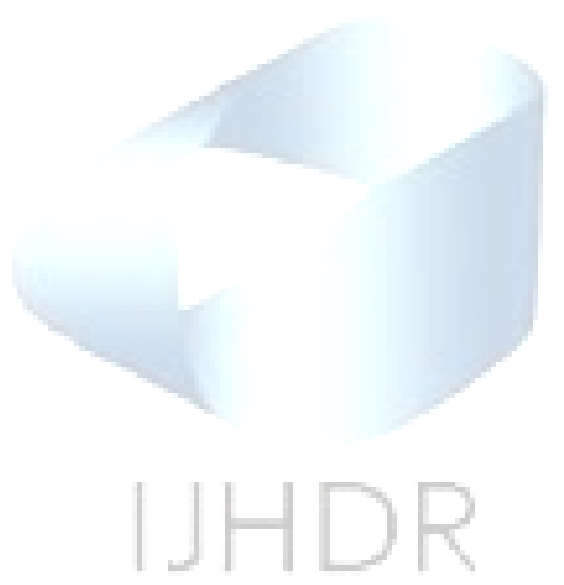

OPEN ACCESS

Cite as: Zhdanova OB, Haidarova AA, Napisanova JA, Rossohin D, Lozhenicina O. The possibility of using T.spiralis as an experimental model in the field of high dilutions. Proceedings of the XXIX GIRI Meeting; 2015 June 3 - 5; Verona (Italy). Int J High Dilution Res. 2015; 14(2): 60-61 